\title{
Gender Sensitive STIs/HIV/AIDS Prevention Policies: A Qualitative Study
}

\author{
Fatemeh Rahmanian1, Masoumeh Simbar ${ }^{2 *}$, Ali Ramezankhani' ${ }^{3}$, Farid Zayeri ${ }^{4}$ \\ ${ }^{1}$ Department of Midwifery and Reproductive Health, Faculty of Nursing and Midwifery, Shahid Beheshti \\ University of Medical Science, Tehran, Iran \\ ${ }^{2}$ The Research Center for Safe Motherhood, Department of Midwifery and Reproductive Health, Shahid \\ Beheshti University of Medical Science, Tehran, Iran \\ ${ }^{3}$ Department of Public Health, Faculty of Health, Shahid Beheshti University of Medical Science, Tehran, Iran \\ ${ }^{4}$ Department of Biostatistics, Faculty of Paramedicine, Shahid Beheshti University of Medical Sciences, Tehran, \\ Iran \\ Email: ${ }^{*}$ msimbar@gmail.com, ${ }^{*}$ msimbar@yahoo.com
}

Received 4 April 2014; revised 7 May 2014; accepted 15 May 2014

Copyright (C) 2014 by authors and Scientific Research Publishing Inc.

This work is licensed under the Creative Commons Attribution International License (CC BY). http://creativecommons.org/licenses/by/4.0/

cC) (7) Open Access

\begin{abstract}
Background: The global incidence of STIs is rising. It is estimated that 499 million new cases of curable STIs occur every year. The existence of more than one million reported cases of STIs annually in Iran shows that addressing this issue must be a priority for Iranian health authorities. While recognition of the importance of gender issues to reproductive health $(\mathrm{RH})$ programs has grown significantly in the past several years, major challenges remain in implementing gendersensitive programs. Gender mainstreaming in Iranian reproductive health program is a relatively new issue, so this study aims to explore gender sensitive STIs/HIV/AIDS prevention policies. Method: This study employed a qualitative research design. Participants were health managers, health policy makers and reproductive health providers. They were selected purposefully and then continued by snowball sampling method. 43 semi-structured in-depth interviews with 37 key informants were done. All the interviews were recorded and transcribed. The data were analyzed by content analysis method. Trustworthiness of the data was achieved by using credibility, transferability and conformability. Results: Key informants clearly explained the gender sensitive STIs/ HIV/AIDS prevention policies in three main categories: 1) advocacy, 2) collaboration between different sectors and 3) community empowerment to gender sensitive STIs/HIV/AIDS prevention programs. Conclusion: Changing gender neural STIs/HIV/AIDS prevention policy to more complete gender sensitive policy needs advocacy, collaboration of sectors and community empowerment.
\end{abstract}

\section{Keywords}

Gender, Gender Sensitive, STIs/HIV/AIDS Prevention, Policies, Qualitative Study

\footnotetext{
${ }^{*}$ Corresponding author.
} 


\section{Background}

The global incidence of STIs is rising [1]-[4], it is estimated that 499 million new cases of curable STIs (gonorrhoea, chlamydia, syphilis and trichomoniasis) occur every year, in addition, 536 million people are estimated to be living with incurable herpes simplex virus type 2 (HSV-2) infection and approximately 291 million women have a human papillomavirus (HPV) infection at any given point in time. Despite the availability of several simple, cheap and cost-effective interventions to combat STIs, little progress has been made [5]. At the end of 2010, some 34 million people were suffering from HIV, of which women constituted $50 \%$ to $64 \%$ of the adults bearing HIV [6]. In America from 1993 to 2003, HIV infection rate raised 15\% in women but 1\% in men [7].

There are an increasing number of sexually transmitted infections in Islamic Republic of Iran during recent years. The annual number of symptomatic reported cases has 8 times increase from 1998 to 2006 reaching about 1.6 incident cases in one-hundred populations. The average annual growth rate in last 6 years was 17\% [8]. More recently, there has been some evidence of the growing role of sexual transmission in the spread of HIV in Iran [9]. The existence of more than one million reported cases of STIs annually in Iran shows that addressing this issue must be a priority for Iran's health authorities. An alarming level of risky sexual contact among young unmarried people, and frequency of condom use unsatisfaction in commercial sex were reported in recent surveys. Therefore, developing and implementing programs for STIs prevention and control are considered as a health priority [8].

The biological, social, cultural, economic, and gender-based factors that contribute to women's vulnerability to HIV/AIDS and other STIs are well documented [10]-[12]. Worldwide, the burden of sexually transmitted infections among women is more than five times that in men [13].

Studies repeatedly show that men who adhere to rigid notions of manhood, who equate masculinity with risk taking, dominance, and sexual conquest [14]. Moreover, men may be reluctant to seek medical information and services because of gender norms that portray health seeking behavior as weak and not masculine. The traditional individual focus on women has treated women's risk behavior as separate from men's, ignoring gender dynamics and the sociocultural context in which heterosexual risk behavior occurs [15] [16].

Failure to access such services negatively impacts men and their partner. Distinct gender roles and behaviors for men and women can lead to inequities in both health status and access to health care [10].

Evaluations of a number of interventions to reduce HIV/AIDS and STIs provide strong evidence that addressing gender norm, promoting policies and programs to extend equality illegal rights, and expanding services for women and men can result in improved HIV/AIDS and gender outcomes [17].

A few studies consider gender sensitive reproductive health. Tuelimishane project in Tanzania has used the workshops and focused group discussion aimed at promoting young men and women attitude towards gender norms, gender-based violence and gender-based risky sexual behavior. It found that young men in the intervention community were significantly more likely to have a condom and favorably changed their attitudes regarding gender norms [18]. "Stepping Stones Project", which has been used in over 40 countries, brings men and women together to discuss gender, health, and HIV/AIDS issues and how they are important for the well-being of all. In South Africa, the program has helped reduce violence against women, made men's attitudes toward women more equitable, and by promoting increased condom use and reductions in individuals' numbers of sexual partners, helped reduce sexually transmitted infections in women [19]. The results of an Iranian qualitative study showed that gender norms and unsupportive roles of husbands were the main obstacles of condom use among high-risk women [20]. While the role of gender-based power in sexual relationships has been acknowledged, the understanding has largely lacked practical considerations in the STIs/HIV/AIDS prevention field in recent years.

While recognition of the importance of gender issues to reproductive health (RH) programs has grown significantly in the past several years, major challenges in implementing gender-sensitive programs remain and most policy makers do not make gender specific plans for prevention policy as epidemics progress.

Gender mainstreaming in Iranian reproductive health program is relatively a new issue so this study aims to explore gender sensitive STIs/HIV/AIDS prevention policy concepts and dimensions.

\section{Methodology}

This qualitative study is the part of an explorative sequential qualitative-quantitative study. Participants were selected purposefully and continued by snow-ball sampling. Thirty seven key informants were interviewed (13 
male, 24 female), including policymakers, program managers, faculties, and health care providers in the reproductive health fields such as safe motherhood, family planning, youth and adolescence health, pre-marriage counseling and STIs/HIV/AIDS prevention services. By permission of Shahid Beheshti Medical Science University, we conducted the interviews in the state clinics and the managers' offices in Shiraz and Tehran.

Data collected by using semi-structured in depth interview. The validity of interview guide questions was confirmed by three experts of reproductive health. All participants took part in the study with written informed consent. Interviews were face-to-face and audio-recorded. Each interview took 60 to 90 minutes. Sometimes supplementary interview was needed to explore complete perception. Interviews were continued till data saturation. Finally 43 interviews were done. The data was analyzed according to conventional content analysis method.

All interviews recorded, typed and coded in the same day. The second interview was done only after coding the first one. Before coding the data, the researchers read the typed interview transcripts and field notes line by line and word by word. Initial coding was done by Straus and Corbin [21] method according to concepts of data. In consideration to cultural diversity and specify of gender concept, the main messages of interviews were explored by reading and re-reading the meaning units. Then similar or related codes were classified to a particular group and subcategories and categories were emerged.

The credibility of the study was promoted by showing codes to participants to be assured about correct perception of their views, appropriate communication between researcher and participants, using various participants with substantial experience and experience from among health care providers, staff members and medical managers, and also to maximize variability in terms of sex, age, and working experience. Transferability was increased by clear and distinct description of selection and characteristics of participants, data collection and process of analysis. To facilitate conformability, audio files, coded printed interviews, notes, analysis and trustworthiness process of the study were documented. The data and records were revised by two reproductive health expert researchers to justify about similarities of results. In more than $90 \%$ of findings, similarities acquired.

\section{Results}

43 semi-structured in depth interviews were done with 37 key informants including reproductive health policy makers, managers and providers. The participants characteristics are presented in Table 1.

Three main categories were formed as: advocacy for gender sensitive STIs/HIV/AIDS prevention programs, collaboration of different systems for gender sensitive programs and community empowerment for promotion of gender sensitive STIs/HIV/AIDS prevention programs (Table 2).

\subsection{Advocacy for Gender Sensitive STIs/HIV/AIDS Prevention Programs}

Participants explored their perception to advocate policy by following statements:

1) Developing a comprehensive reproductive and sexual education program:

Most of participants underscore the importance of developing a comprehensive reproductive and sexual educational program focusing on gender norms:

"Up to now, we have been lacking of a comprehensive reproductive and sexual education program. An understanding of what to teach and at what age, is also of great importance. Reproductive and sexual education must be adapted to gender norms and different preparation." (Health manager with 24 years experience)

2) Developing skill based sexual educational program:

30 of the participants emphasized on promotion of the skill based sexual education program:

"Effective adolescents' preventive programs help them to promote communication and negotiation skills to identify their own values and to modify their risky sexual behavior." (Adolescents health manager with 12 years experience)

3) Developing STIs/HIV/AIDS partner notification strategy:

The significance of STIs/HIV/AIDS partner notification strategy was stated by 26 interviews:

"We lack any partner notification strategy in case of STIs/HIV/AIDS infection. We have this responsibility about the patient. Women afraid of stigma and isolation attached to these diseases and men also afraid of displaying their weakness and illness, thereby the disease will remain hidden and spread." (Family health provider with 12 years experience)

4) Overcoming gender related taboos that act as the barriers of education and reporting sexual problems: 
Table 1. The participants' characteristics.

\begin{tabular}{ccc}
\hline & Character & No \\
\hline & Reproductive health manager and policy makers & 13 \\
Occupation & Faculties & 10 \\
& Reproductive health provider & 14 \\
Sex & Male: & 13 \\
Age (years) & Female: & 24 \\
Experience (years) & Range: $33-60$ & \\
\end{tabular}

Table 2. Theme, categories and codes extracted from reproductive health managers and providers perception towards gender sensitive STIs/HIV/AIDS prevention policies.

\begin{tabular}{|c|c|c|}
\hline THEME & CATEGORIES & CODES \\
\hline \multirow{18}{*}{$\begin{array}{l}\text { Gender sensitive } \\
\text { STIs/HIV/AIDS } \\
\text { prevention policies }\end{array}$} & \multirow{10}{*}{$\begin{array}{l}\text { Advocacy for gender } \\
\text { sensitive STIs/HIV/AIDS } \\
\text { prevention programs }\end{array}$} & Developing a comprehensive reproductive and sexual education program \\
\hline & & Developing skill based sexual educational program \\
\hline & & Developing STIs/HIV/AIDS partner notification strategy \\
\hline & & $\begin{array}{l}\text { Overcoming gender related taboos that act as the barriers of education and } \\
\text { reporting sexual problems }\end{array}$ \\
\hline & & Integrating abstinence only programs by other risk reduction programs \\
\hline & & Developing post rape exposure risk reduction interventions \\
\hline & & Having educational program about condom use via television and radio \\
\hline & & Developing sexual health education and overcome barriers \\
\hline & & Revising STIs national rules that encourage hiding of these cases \\
\hline & & Making reproductive services more available to single women \\
\hline & \multirow{4}{*}{$\begin{array}{l}\text { Collaboration of different } \\
\text { systems for gender sensitive } \\
\text { programs }\end{array}$} & Developing sexual health education at school and overcome the barriers \\
\hline & & Integrating STI prevention program to occupational health \\
\hline & & $\begin{array}{l}\text { Collaboration between governmental and private sectors in STIs/HIV/ADS } \\
\text { prevention programs }\end{array}$ \\
\hline & & Implementation sexual behavior researches by universities \\
\hline & \multirow{4}{*}{$\begin{array}{l}\text { Community empowerment } \\
\text { for promotion of gender } \\
\text { sensitive STIs/HIV/AIDS } \\
\text { prevention programs }\end{array}$} & Educating parents to promote adolescents sexual health \\
\hline & & Effective and timely education in STI prevention \\
\hline & & $\begin{array}{l}\text { Removing barriers to an effective and appropriate sexual education for all } \\
\text { people }\end{array}$ \\
\hline & & $\begin{array}{l}\text { Adolescents' reproductive health needs assessment for sexual education } \\
\text { planning }\end{array}$ \\
\hline
\end{tabular}

More than half of the participants agreed that the gender related taboos should be tackled:

“When I visit female schools the managers don't permit me to talk about STIs, they deny sexual activities among the students, and if there are any, it may affect the school reputation. They afraid of stigmatization but when students are asked questions I find implicitly some cases of STIs while they can't talk about it with their mothers. Male students, on the other hand, talk freely about their sexual activities but disclosing STIs is considered as weakness and disempowerment, thereby they don't refer to clinics." (Adolescents health manager with 8 years experience)

2 of the participants talked about gender related barriers to STIs reporting:

"Regarding a case of STIs infected person, a question which is raised is that how s/he has afflicted? Any replying to this question will lead to his or her partner (they may be homosexual). Nevertheless they are afraid of being disclosed, so he or she will not follow the case and may do anything about revealing his or her disease." 
(Health behavior diseases specialist with 10 years experience)

5) Integrating abstinence only programs by other risk reduction programs:

Developing a holistic risk reduction strategy such as abstinence promotion programs and condom use and reducing sexual partners was noted in the most interviews:

"We educate abstinence only programs from sexual activity; such programs do not present positive information about condom use and reduce sexual partners. We have neglected the youth needs; they commit sexual activity using our negligence. Youth need to be aware of the risks. However, we don't permit ourselves to work in this field." (STIs prevention provider with 40 years experience)

6) Developing post rape exposure risk reduction interventions

12 of the participants mentioned to negative effects of lacking post rape risk reduction intervention for girls:

"In the case of sexual assault, the girls do not know where to refer to or they may afraid of stigmatization; so later on, while some of them refer to us, their HIV test result is positive. Perhaps, if they referred earlier they could be treated by post exposure anti retroviral therapy that prevents illness." (Health behavior diseases specialist with 6 years experience)

7) Having educational program about via television and radio:

15 of the participants talked about radio and television restriction on such programs as condom use education:

"Policy in our media is so as we cannot even name condom in the radio or TV; I think it is our preliminary problem. We can't educate protective ways in sexual activity via TV or radio." (Family health chief manager with 15 years experience)

Conversely, 3 of participants approved current policy:

"If we educate the young how to use condom and contraceptive methods in addition to abstinence only program, we implicitly encourage them to have sexual activities." (Family health manager with 15 years experience)

8) Developing sexual health education and overcome barriers:

32 of the participants addressed occasional negative roles of media in STIs/HIV/AIDS prevention programs:

"Sometimes, we come across films broadcast by TV, in which some sexual hints, though unpurposefully, alert teens to follow; or also showing the films that their themes approve and justify polygamy. Such films should be supervised, in advance, by health care policy makers." (STIs prevention provider with 6 years experience)

9) Revising STIs national rules that encourage hiding of these cases:

One of participants mentioned to a national rule that encourage hiding of cases of STIs infection in labor force:

"Past national rule (1939) prohibited those with STIs to continue working unless they get rid of the infection. So they hide their infection because of low economic situation. The rules should be revised. For example, if a worker infected by STIs such as syphilis or gonorrhea, he cant work until his treatment." (STIs prevention manager with 20 years experience)

10) Making reproductive services more available to single women:

Responding to single women needs mentioned by 12 of participants:

"Our reproductive policy makers don't include single women in their programs, while they are more vulnerable to STIs. Their problems are hidden without taking any services." (Family health provider with 20 years experience)

\subsection{Gender Sensitive STIs/HIV Preventive Collaboration between Different Systems}

Data in this category were coded as follows:

1) Developing sexual health education at school and overcome the barriers:

Developing sexual health education is stressed by 31 of the participants:

"Although schools are considered to be the first place to initiate sexual health education, the ministry of education prohibits any such educations." (Health policy maker with 12 years experience)

2) Integrating STI prevention program to occupational health:

The importance of integration STI prevention program to occupational health was emphasized by 20 of the participants:

"Providers must seek men through mobile outreach. Often this approach can implement via an existing clinic, such as workplace clinics." (Health policy maker with 23 years experience) 
3) Collaboration between governmental and private sectors in STIs/HIV/AIDS prevention programs:

Almost all participants emphasized the importance of collaborations between state and private sections in STIs/HIV/AIDS preventive programs:

"Lack of privacy in governmental STIs clinics encourage clients to go to private clinics. There is no partnership between governmental and private sectors... sexual stimulating medicines distribute in pharmacies... these medicines increase rate of STIs by prolong sexual exposure especially in commercial sex... but we as health care providers aren't familiar with them." (STIs prevention manager with 15 years experience)

4) Implementation sexual behavior researches by universities membrane:

22 of the participants who work at academic institutions said:

"Few studies are conducted in our universities in terms of sexual behaviors. It is perhaps we deny the happening of such unaccepted behaviors in our society. Thus our interventions are mostly superficial, and in most cases unsuccessful." (Faculty member with 20 years experience)

\subsection{Gender Sensitive Community Empowerment}

32 of the participants asserted the creation of enabling environments in these domains:

1) Educating parents to promote adolescents sexual health:

A majority of participants focused the positive roles of parents for sexual health promotion among youth:

"While parents are the best choice for making their children aware of sexual issues, no substantial efforts are done to teach parents in this regard by health care providers." (Health policy with 17 years experience)

Some participants mentioned to disagreement of medical staff with parents-adolescents communication about sexual issues:

"My physicians' coworkers who have young adolescents don't agree with our published puberty booklet, they find it unnecessary to discuss sexual issues with their children, they fear of damaging their privacy." (Adolescents health manager with 8 years experience)

2) Effective and timely education in STI prevention:

33 of the participants found the time of sexual health education too late to be effective:

"Sexual issues should be educated prior to first sexual activity but we want to be complacent that the young have no sexual relation before marriage. That is why we begin our education only before marriage."

3) Removing barriers to an effective and appropriate sexual education for all people:

34 of the participants emphasized on the inefficiency of traditional approach to educating programs:

"Without paying attention to gender sensitivity, educating men's and women's right is ineffective. Prevention programs education without considering reproductive rights aren't effective. We should not think that our educational activities happen in gender equitable environment. We must be sensitive to the fact that men may have multiple sex partners and women don't have the right to object." (Faculty member with 12 years experience)

4) Adolescents' reproductive health needs assessment for sexual education planning:

All participants emphasized on meeting adolescents' reproductive health needs assessment:

"Adolescents must come to clinic for the student routine check up, just to complete the health forms. There is some physical check up items, and other check ups dealing with depression but there is no single check up item for their reproductive and sexual behavior." (Adolescents health provider with 8 years experience)

\section{Discussion}

This was the first study to explore appropriate policies for gender sensitive STIs/HIV/AIDS prevention promotion using a qualitative in Iran. One of the concepts emphasized in this study, regarding gender sensitive STIs/ HIV/AIDS prevention policy is advocacy. Advocacy is an effort to change public perceptions about comprehensive sexuality education, a key element to STIs prevention. We found that information on sexuality alone is not enough, and therefore political support of gender sensitive sexual education training in these controversial topics despite social sanctions is necessary. Successful intervention of teaching of comprehensive reproductive health in Sirilanka [22] also emphasizes its role. Our findings suggest that social stigma and abstinence-only education restricted adolescents access to information and services. Another study confirmed that abstinence-plus education programs should be more effective than abstinence-only education programs because the former acknowledged that many teenagers would become sexually active, teach about contraception and condom use and discussions about abortion, STIs/HIV/AIDS [23]. 
Our data provide a perception to partner notification advantages for STI prevention, as they mentioned to partner notification as the most effective method for STIs/HIV/AIDS prevention and transmission is not defined clearly by health policy at the national level programs. Relevant studies showed the contribution of partner notification to STI prevention results in earlier treatment and education, and decreased reinfection rates in index cases [24]-[26].

The results showed a silent socio-cultural norm in our society, evident in the barrier role of radio and television in condom use encouragement for STIs/HIV/AIDS prevention. Tanzanian studies found increased of condoms use was associated with exposure to radio and television programs [27] [28] and furthers case studies and field experiences confirmed that Internet and other technologies have been useful for augmenting STI/HIV prevention and intervention activities for reaching particular demographic groups [29] [30].

Although risk reduction strategies were mentioned by participants, they discussed that health policy-makers' indifference towards the role of stigma, discrimination and human rights will result in the secretiveness of sexually transmitted diseases as a consequence of hidden sexual relations. The related body of research also confirmed the role of social support in informing spouses [31] [32], disclosure of the STIs/HIV/AIDS [33] [34] and promotion of education of girls in regard to sexual issues [35].

Finding showed a necessity for collaboration between different systems in the areas of school health, occupational health and STIs private sector. Global interventions show that schools' health [36] and the merging of the prevention of STIs through educating counterparts among workers of large companies [37] [38] can play an effective role in this relation.

The results demonstrated that little is known about current STIs/HIV/AIDS practices outside of governmental STD clinics. Diversity in how physicians handle STIs/HIV/AIDS counseling, screening, testing and treating results in dispersed STIs/HIV/AIDS prevention objects. Another survey of primary care physicians found many missed opportunities to diagnose, treat, or prevent STDs in the United States [39].

The study highlighted that understanding the nature of sexual behaviors and their social determinants by academic research, is key to designing more effective STIs/HIV/AIDS prevention programs. Our findings were similar to Coates et al. study [40] that showed STIs/HIV/AIDS prevention success was substantially improved when HIV prevention addresses the broader structural factors that shape or constrain individual behavior, such as poverty and wealth, gender, age, policy, and power.

In community empowerment domain, our findings suggest a need for reproductive health educational policy designed to facilitate communication between parents and adolescents. A large proportion of studies mainly from developed countries conducted on how parents influence adolescent sexual behavior [41]-[45]. Participants also described the importance of overcoming barriers to sexual and reproductive health education. Socio-cultural taboos connected to it and lack of correct knowledge makes open discussions difficult. Participants highlighted the importance of gender-based life skills education in school health. Worldwide UNICEF studies show the importance of encouraging positive values in relationships, such as assertiveness and self-confidence, particularly among girls, and learning to listen and show respect, particularly among boys [46].

\section{Conclusion}

In our country, transforming gender neural to more complete gender sensitive STIs/HIV/AIDS prevention policy needs reforms that make these interventions more effective.

\section{References}

[1] Miners, A., Llewellyn, C., Pollard, A., Lagarde, M., Richardson, D., Cairns, J., Fisher, M. and Smith, H. (2012) Assessing User Preferences for Sexually Transmitted Infection Testing Services: A Discrete Choice Experiment. Sexually Transmitted Infections, 88, 510-516. http://dx.doi.org/10.1136/sextrans-2011-050215

[2] Surveillance of STIs (2005) A Report by the Sexually Transmitted Infections Subcommittee for the Scientific Advisory Committee of the Health Protection Surveillance Centre. Health Protection Surveillance Centre, Dublin.

[3] Mayaud, P. and Mabey, D. (2004) Approaches to the Control of Sexually Transmitted Infections in Developing Countries: Old Problems and Modern Challenges. Sexually Transmitted Infections, 80, 174-182. http://dx.doi.org/10.1136/sti.2002.004101

[4] Lazaro, N. (2010) Management of Sexually Transmitted Infections in Non-Specialist Settings: Practical Issues. Medicine, 38, 322-327. http://dx.doi.org/10.1016/j.mpmed.2010.02.004 
[5] Sexually Transmitted Infections (STIs) (2013) The Importance of a Renewed Commitment to STI Prevention and Control in Achieving Global Sexual and Reproductive Health. WHO, Geneva.

[6] World Health Organization (WHO), UNAIDS and UNICEF (2011) Global HIV/AIDS Response: Epidemic Update and Health Sector Progress towards Universal Access: Progress Report 2011. WHO, Geneva.

[7] HIV/AIDS Surveillance (2003) Centers for Disease Control, National Center for Infectious Diseases, Division of HIV/AIDS. US Department of Health and Human Services, Washington DC.

[8] Ministry of Health and Medical Education (MOHME) and HIV/STI Office (2008) Situation Analysis of Sexually Transmitted Infections in the Islamic Republic of Iran.

[9] Ministry of Health and Medical Education (MOHME) and National AIDS Committee Secretariat (2012) Islamic Republic of Iran AIDS Progress Report.

[10] UNAIDS (2003) Aids Epidemic Update: 2003. World Health Organization, Geneva.

[11] Uwe, E.A., Ekuri, E.E. and Asuquo, P.N. (2006) African Women and Vulnerability to HIV/AIDS: Implications for Female Related Cultural Practices. International Quarterly of Community Health Education, 27, 87-94. http://dx.doi.org/10.2190/IQ.27.1.g

[12] Maman, S., Campbell, J., Sweat, M.D. and Gielen, A.C. (2000) The Intersections of HIV and Violence: Directions for Future Research and Interventions. Social Science \& Medicine, 50, 459-478. http://dx.doi.org/10.1016/S0277-9536(99)00270-1

[13] Sciarra, J.J. (2009) Global Issues in Women’s Health. International Journal of Gynaecology and Obstetrics: The Official Organ of the International Federation of Gynaecology and Obstetrics, 104, 77-79.

[14] Peacock, D., Stemple, L., Sawires, S. and Coates, T.J. (2009) Men, HIV/AIDS, and Human Rights. Journal of Acquired Immune Deficiency Syndromes, 51, S119-S125.

[15] Sayles, J.N., Pettifor, A., Wong, M.D., MacPhail, C., Lee, S.J., Hendriksen, E., Rees, H.V. and Coates, T. (2006) Factors Associated with Self-Efficacy for Condom Use and Sexual Negotiation among South African Youth. Journal of Acquired Immune Deficiency Syndromes, 43, 226-233.

[16] Baiden, P. and Rajulton, F. (2011) Factors Influencing Condom Use among Women in Ghana: An HIV/AIDS Perspective. Journal of Social Aspects of HIV/AIDS Research Alliance/SAHARA, 8, 46-54.

[17] USAID (2011) A Summary Report of New Evidence That Gender Perspectives Improve Reproductive Health Outcomes. http://www.prb.org/igwg_media/summary-report-gender-perspectives.pdf

[18] Maganja, R.K., Maman, S., Groves, A. and Mbwambo, J.K. (2007) Skinning the Goat and Pulling the Load: Transactional Sex among Youth in Dar es Salaam, Tanzania. AIDS Care, 19, 974-981. http://dx.doi.org/10.1080/09540120701294286

[19] Jewkes, R., Nduna, M., Levin, J., Jama, N., Dunkle, K., Khuzwayo, N., Koss, M., Puren, A., Wood, K. and Duvvury, N. (2006) A Cluster Randomized-Controlled Trial to Determine the Effectiveness of Stepping Stones in Preventing HIV Infections and Promoting Safer Sexual Behaviour amongst Youth in the Rural Eastern Cape, South Africa: Trial Design, Methods and Baseline Findings. Tropical Medicine \& International Health, 11, 3-16. http://dx.doi.org/10.1111/j.1365-3156.2005.01530.x

[20] Lotfi, R., Tehrani, F.R., Yaghmaei, F. and Hajizadeh, E. (2012) Barriers to Condom Use among Women at Risk of HIV/AIDS: A Qualitative Study from Iran. BMC Women's Health, 12, 13. http://dx.doi.org/10.1186/1472-6874-12-13

[21] Corbin, J. and Strauss, A. (1990) Basics of Qualitative Research: Grounded Theory Procedures and Techniques. Sage, Thousand Oaks.

[22] Agampodi, S.B., Agampodi, T.C. and Ukd, P. (2008) Adolescents Perception of Reproductive Health Care Services in Sri Lanka. BMC Health Services Research, 8, 98. http://dx.doi.org/10.1186/1472-6874-12-13

[23] Collins, C., Alagiri, P., Summers, T. and Morin, S. (2002) Abstinence Only vs. Comprehensive Sex Education: What Are the Arguments? What Is the Evidence? http://www.ebooksoneverything.com/youth/abstinencevssexeducation.pdf

[24] Trelle, S., Shang, A., Nartey, L., Cassell, J.A. and Low, N. (2007) Improved Effectiveness of Partner Notification for Patients with Sexually Transmitted Infections: Systematic Review. BMJ: British Medical Journal, 334, 354.

[25] Cohen, D.A., Wu, S.Y. and Farley, T.A. (2004) Comparing the Cost-Effectiveness of HIV Prevention Interventions. Journal of Acquired Immune Deficiency Syndromes, 37, 1404-1414.

[26] Radcliffe, K. and Clarke, J. (1998) Contact Tracing-Where Do We Go from Here? Sexually Transmitted Infections, 74, 313-315.

[27] Shapiro, D., Meekers, D. and Tambashe, B. (2003) Exposure to the "SIDA dans la Cité" AIDS Prevention Television Series in Côte' d'Ivoire, Sexual Risk Behaviour and Condom Use. AIDS Care, 15, 303-314. http://dx.doi.org/10.1080/0954012031000105360 
[28] Vaughan, P.W., Rogers, E.M., Singhal, A. and Swalehe, R.M. (2000) Entertainment-Education and HIV/AIDS Prevention: A Field Experiment in Tanzania. Journal of Health Communication, 5, 81-100. http://dx.doi.org/10.1080/10810730050019573

[29] Lim, M.S., Hocking, J.S., Hellard, M.E. and Aitken, C.K. (2008) SMS STI: A Review of the Uses of Mobile Phone Text Messaging in Sexual Health. International Journal of STD \& AIDS, 19, 287-290. http://dx.doi.org/10.1258/ijsa.2007.007264

[30] Swendeman, D. and Rotheram-Borus, M.J. (2010) Innovation in Sexually Transmitted Disease and HIV Prevention: Internet and Mobile Phone Delivery Vehicles for Global Diffusion. Current Opinion in Psychiatry, 23, 139-144. http://dx.doi.org/10.1097/YCO.0b013e328336656a

[31] Semrau, K., Kuhn, L., Vwalika, C., Kasonde, P., Sinkala, M., Kankasa, C., Shutes, E., Aldrovandi, G. and Thea, D.M. (2005) Women in Couples Antenatal HIV Counseling and Testing Are Not More Likely to Report Adverse Social Events. AIDS, 19, 603-609. http://dx.doi.org/10.1097/01.aids.0000163937.07026.a0

[32] Homsy, J., Kalamya, J.N., Obonyo, J., Ojwang, J., Mugumya, R., Opio, C. and Mermin, J. (2006) Routine Intrapartum HIV Counseling and Testing for Prevention of Mother-to-Child Transmission of HIV in a Rural Ugandan Hospital. Journal of Acquired Immune Deficiency Syndromes, 42, 149-154.

[33] Pulerwitz, J., Michaelis, A., Verma, R. and Weiss, E. (2010) Addressing Gender Dynamics and Engaging Men in HIV Programs: Lessons Learned from Horizons Research. Public Health Reports, 125, 282-292.

[34] Waddell, E.N. and Messeri, P.A. (2006) Social Support, Disclosure, and Use of Antiretroviral Therapy. AIDS and Behavior, 10, 263-272. http://dx.doi.org/10.1007/s10461-005-9042-x

[35] Uddin, M.J. and Choudhury, A.M. (2008) Reproductive Health Awareness among Adolescent Girls in Rural Bangladesh. Asia-Pacific Journal of Public Health, 20, 117-128.

[36] Borgia, P., Marinacci, C., Schifano, P. and Perucci, C.A. (2005) Is Peer Education the Best Approach for HIV Prevention in Schools? Findings from a Randomized Controlled Trial. The Journal of Adolescent Health, 36, 508-516.

[37] Cornman, D.H., Schmiege, S.J., Bryan, A., Benziger, T.J. and Fisher, J.D. (2007) An Information-Motivation-Behavioral Skills (IMB) Model-Based HIV Prevention Intervention for Truck Drivers in India. Social Science \& Medicine, 64, 1572-1584.

[38] Witte, K., Cameron, K.A., Lapinski, M.K. and Nzyuko, S. (1998) A Theoretically Based Evaluation of HIV/AIDS Prevention Campaigns along the Trans-Africa Highway in Kenya. Journal of Health Communication, 3, 345-363. http://dx.doi.org/10.1080/108107398127157

[39] Tao, G., Irwin, K.L. and Kassler, W.J. (2000) Missed Opportunities to Assess Sexually Transmitted Diseases in US Adults during Routine Medical Checkups. American Journal of Preventive Medicine, 18, 109-114. http://dx.doi.org/10.1016/S0749-3797(99)00139-7

[40] Coates, T.J., Richter, L. and Caceres, C. (2008) Behavioural Strategies to Reduce HIV Transmission: How to Make Them Work Better. Lancet, 372, 669-684. http://dx.doi.org/10.1016/S0140-6736(08)60886-7

[41] Crosby, R.A., DiClemente, R.J., Wingood, G.M., Cobb, B.K., Harrington, K., Davies, S.L., Hook 3rd, E.W. and Oh, M.K. (2001) HIV/STD-Protective Benefits of Living with Mothers in Perceived Supportive Families: A Study of HighRisk African American Female Teens. Preventive Medicine, 33, 175-178. http://dx.doi.org/10.1016/S0140-6736(08)60886-7

[42] Henrich, C.C., Brookmeyer, K.A., Shrier, L.A. and Shahar, G. (2006) Supportive Relationships and Sexual Risk Behavior in Adolescence: An Ecological-Transactional Approach. Journal of Pediatric Psychology, 31, 286-297. http://dx.doi.org/10.1093/jpepsy/jsj024

[43] McNeely, C., Shew, M.L., Beuhring, T., Sieving, R., Miller, B.C. and Blum, R.W. (2002) Mothers’ Influence on the Timing of First Sex among 14- and 15-Year-Olds. The Journal of Adolescent Health, 31, 256-265.

[44] Wight, D., Williamson, L. and Henderson, M. (2006) Parental Influences on Young People’s Sexual Behaviour: A Longitudinal Analysis. Journal of Adolescence, 29, 473-494. http://dx.doi.org/10.1016/j.adolescence.2005.08.007

[45] Voisin, D.R. (2002) Family Ecology and HIV Sexual Risk Behaviors among African American and Puerto Rican Adolescent Males. The American Journal of Orthopsychiatry, 72, 294-302. http://dx.doi.org/10.1037/0002-9432.72.2.294

[46] UNICEF (2002) HIV/AIDS Education: A Gender Perspective, Tips and Tools. UNICEF, New York. 